\title{
Actively caseating endobronchial tuberculosis successfully treated with intermittent chemotherapy without corticosteroid: a report of 2 cases
}

\begin{abstract}
Tuberculous infection of the tracheobronchial tree confirmed by microbiological or histopathological evidence with or without parenchymal involvement is known as endobronchial tuberculosis. Chronic cough is the predominant symptom. Expectorated sputum examination for acid fast bacilli is often negative leading to delay in diagnosis. Therefore, bronchoscopy is crucial for early diagnosis and evaluation of the extent of disease. Bronchostenosis is a significant complication of endobronchial tuberculosis that may be present at the time of diagnosis or develops during the course of treatment. Previously, corticosteroids have been used along with antitubercular therapy to prevent or reduce the extent of bronchostenosis; however, their role is debatable as bronchostenosis often develops despite the use of corticosteroids. Furthermore, the duration of treatment varied from 6-9 months of daily therapy in previous series and little is known about efficacy of intermittent antituberculous therapy. Here we report two cases of actively caseating endobronchial tuberculosis successfully managed with six months of intermittent oral antitubercular therapy without corticosteroids.
\end{abstract}

Key words: tuberculosis, endobronchial tuberculosis, antitubercular drugs, corticosteroid

Adv. Respir. Med. 2017; 85: 322-327

\section{Introduction}

Endobronchial tuberculosis (EBTB) is characterized by tuberculous infection of the tracheobronchial tree that is usually diagnosed by bronchoscopy supplemented with a microbiological or histopathological confirmation. This can occur with or without parenchymal involvement $[1,2]$. The reported incidence varied from $10-38.8 \%$ in earlier studies [3]. Recently EBTB was found in $4.1 \%$ of unselected patients and in $54 \%$ of newly diagnosed pulmonary tuberculosis patients undergoing flexible bronchoscopy [3, 4]. In the absence of parenchymal disease or positive sputum microbiology, patients may be erroneously treated for other causes of chronic cough leading to potential delay in diagnosis and increased risk of transmission in the community [5-7]. There is no consensus on the duration of antitubercular therapy or the use of corticosteroids in EBTB. Most studies have used daily antitubercular treatment for 6-9 months with or without corticosteroids [1-4]. The efficacy of intermittent therapy in EBTB is not known. We could find two studies reporting a total of 4 cases treated with intermittent antitubercular therapy along with corticosteroids [8, 9]. Here we report two cases of actively caseating EBTB successfully treated with 6-month intermittent oral antitubercular therapy without corticosteroids.

\section{Case 1}

A 24-year-old male presented in February 2015 with breathlessness on exertion for 4 years, productive cough and feverishness lasting for two and half years. He had recurrent respiratory symptoms since childhood but denied any treatment for tuberculosis. He never smoked to-

Address for correspondence: Manoj Kumar Panigrahi, All India Institute of Medical Sciences, Bhubaneswar, 751019, Bhubaneswar, India, e-mail: panigrahimanoj75@gmail.com DOI: 10.5603/ARM.2017.0055

Received: 05.05.2017

Copyright (C) 2017 PTChP

ISSN 2451-4934 
bacco or drank alcohol. He worked in a plywood construction factory in the past four years. At presentation his vitals were as follows: pulse rate $80 / \mathrm{min}$, respiration rate $20 / \mathrm{min}$, blood pressure 110/60 $\mathrm{mm} \mathrm{Hg}$ and oxygen saturation 98\% in room air. Physical examination of the chest sho-

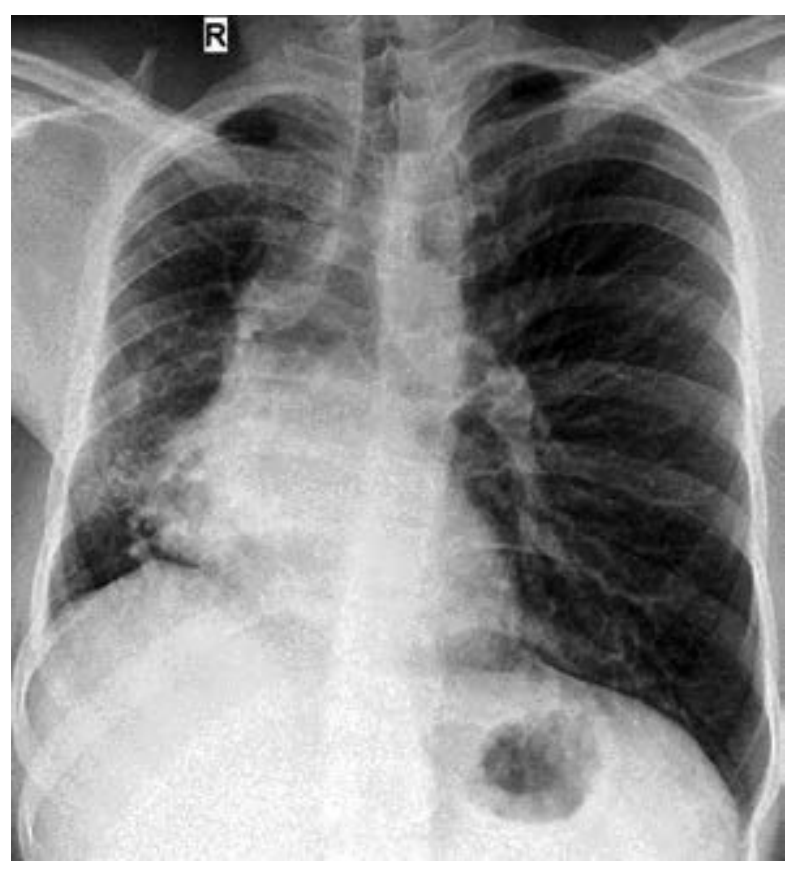

Figure 1. Chest radiograph shows reduced right lung volume, haziness in the right paracardiac border, prominent pulmonary artery and hyperinflation of the left lung wed a shrunken right hemithorax with ipsilateral tracheal deviation. Auscultation revealed diminished vesicular breath sound with inspiratory crackles on a right side. Hemogram showed hemoglobin concentration $14.5 \mathrm{gm} \%$, white cell count $4,900 / \mathrm{cm}$ with differentials of neutrophil $55 \%$, lymphocytes $40 \%$, eosinophil $3 \%$, and monocytes $2 \%$. Blood metabolic panel, fasting blood glucose, liver function test and serum electrolytes were normal. Human immunodeficiency virus serology was negative. Chest radiograph showed reduced right lung volume, ipsilateral mediastinal shift, haziness in the right paracardiac area, prominent pulmonary artery and hyperinflation of the left lung (Fig. 1). Incidentally, contrast enhanced computed tomography (CT) scan demonstrated the main pulmonary artery continued as a single artery supplying the left lung and the right pulmonary artery was absent (Fig. 2A). The right lung volume was reduced with nodular infiltrates in the middle and lower lobes and compensatory hyperinflation of the left lung was evident (Fig. 2B). Flexible bronchoscopy showed curd-white plaques covering the medial wall of the bronchus intermedius and middle and lower lobar openings with mucosal edema, hyperemia and luminal narrowing (Fig. 3A). Bronchial washing smear was positive for acid fast bacilli. Endobronchial biopsy showed granuloma with caseous necrosis and the presence of acid fast bacilli (Fig. 4A, C). Subsequently, expectorated sputum examination
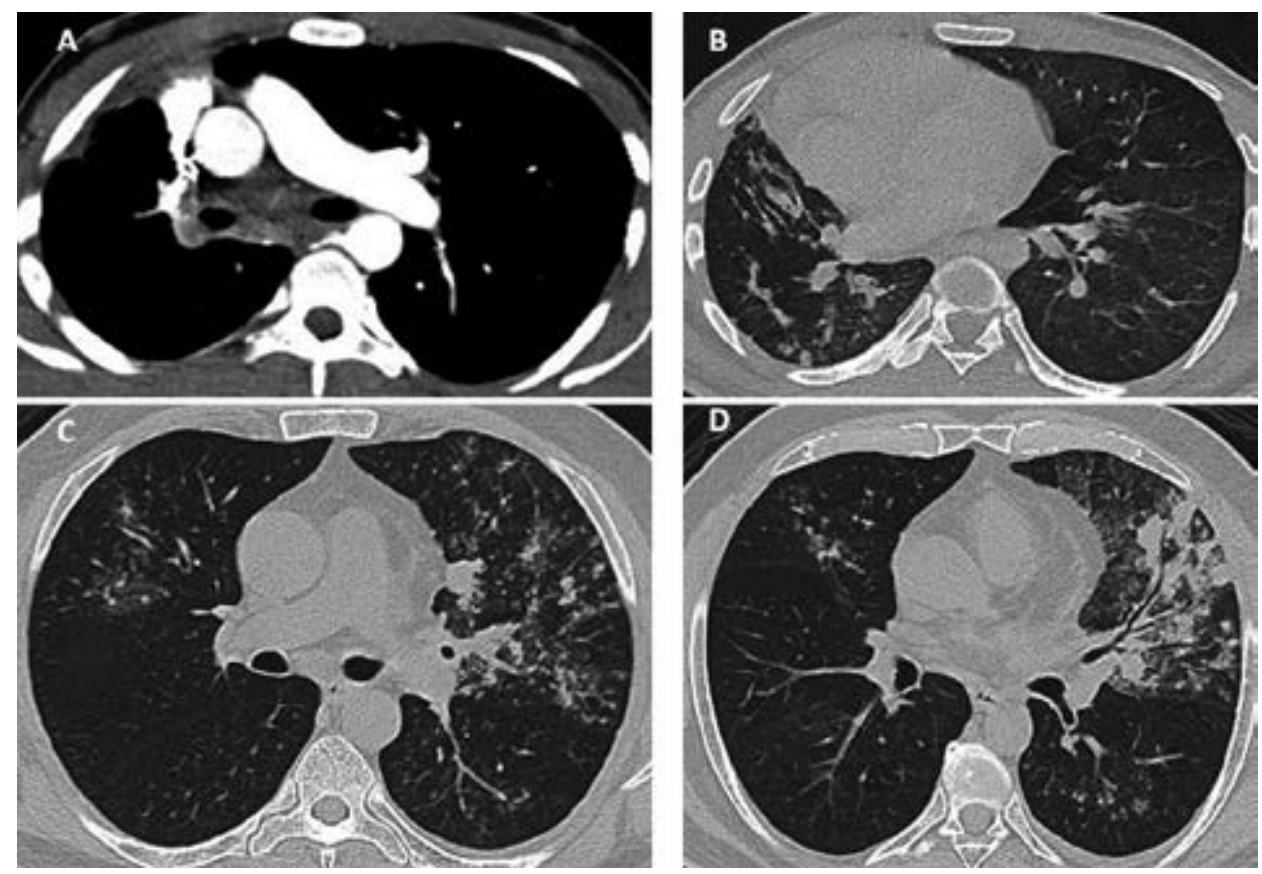

Figure 2. CT scan in case 1 shows (A) agenesis of the right pulmonary artery with hyperinflation of the left lung and (B) right lung hypoplasia with infiltrates in the right middle and lower lobes (C, D) lung window in case 2 demonstrates bilateral infiltrates with lingular consolidation 

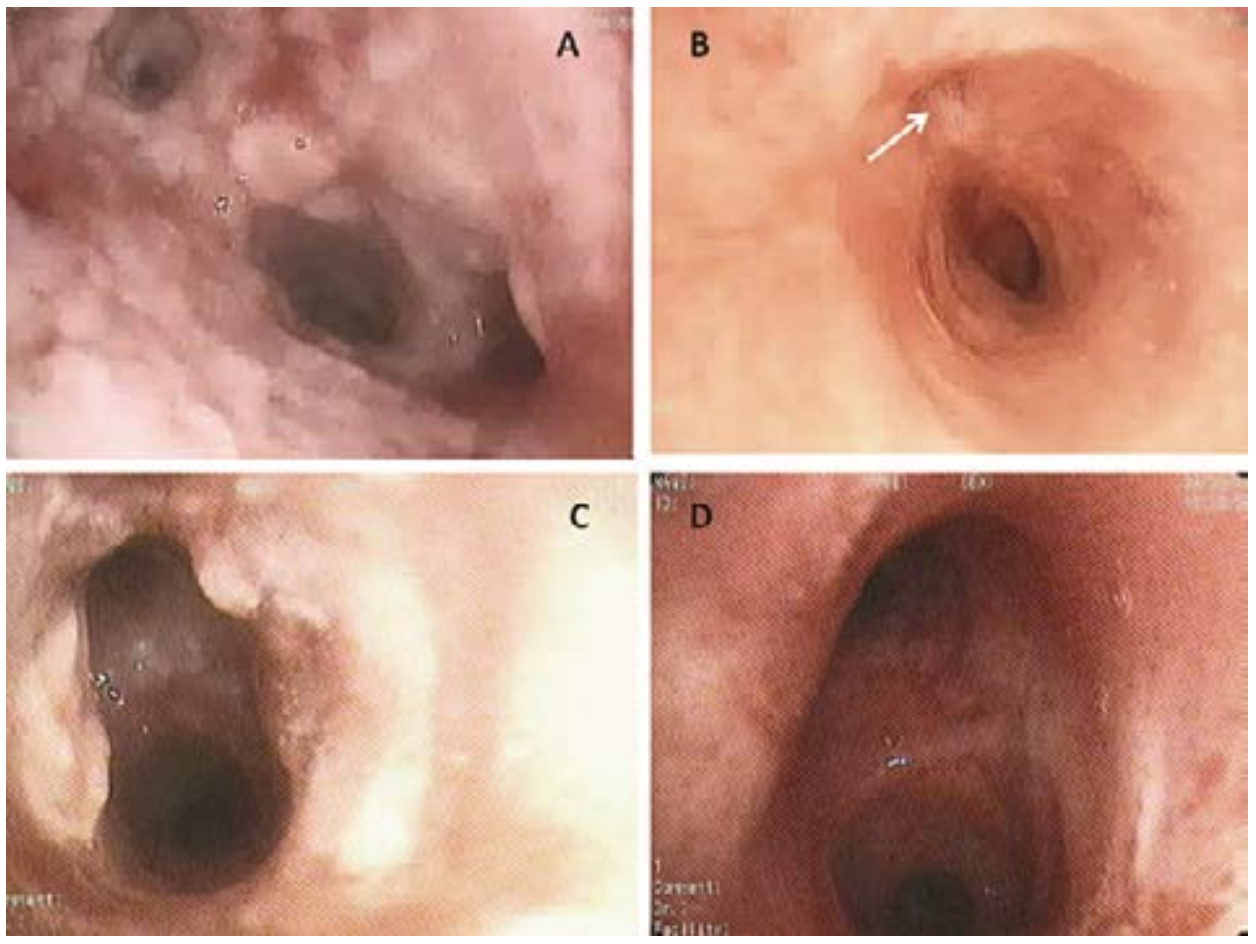

Figure 3. Bronchoscopy in case 1 showed (A) curd-white caseous material diffusely involving the bronchus intermedius, right middle and lower lobes bronchi (B) complete resolution after treatment with significant narrowing of lower lobe bronchus and stenosed middle lobe bronchus (arrow). Bronchoscopy in case 2 showed (C) whitish caseous tissue covering the left upper lobe bronchial surface (D). Complete resolution of pathology after treatment without bronchostenosis

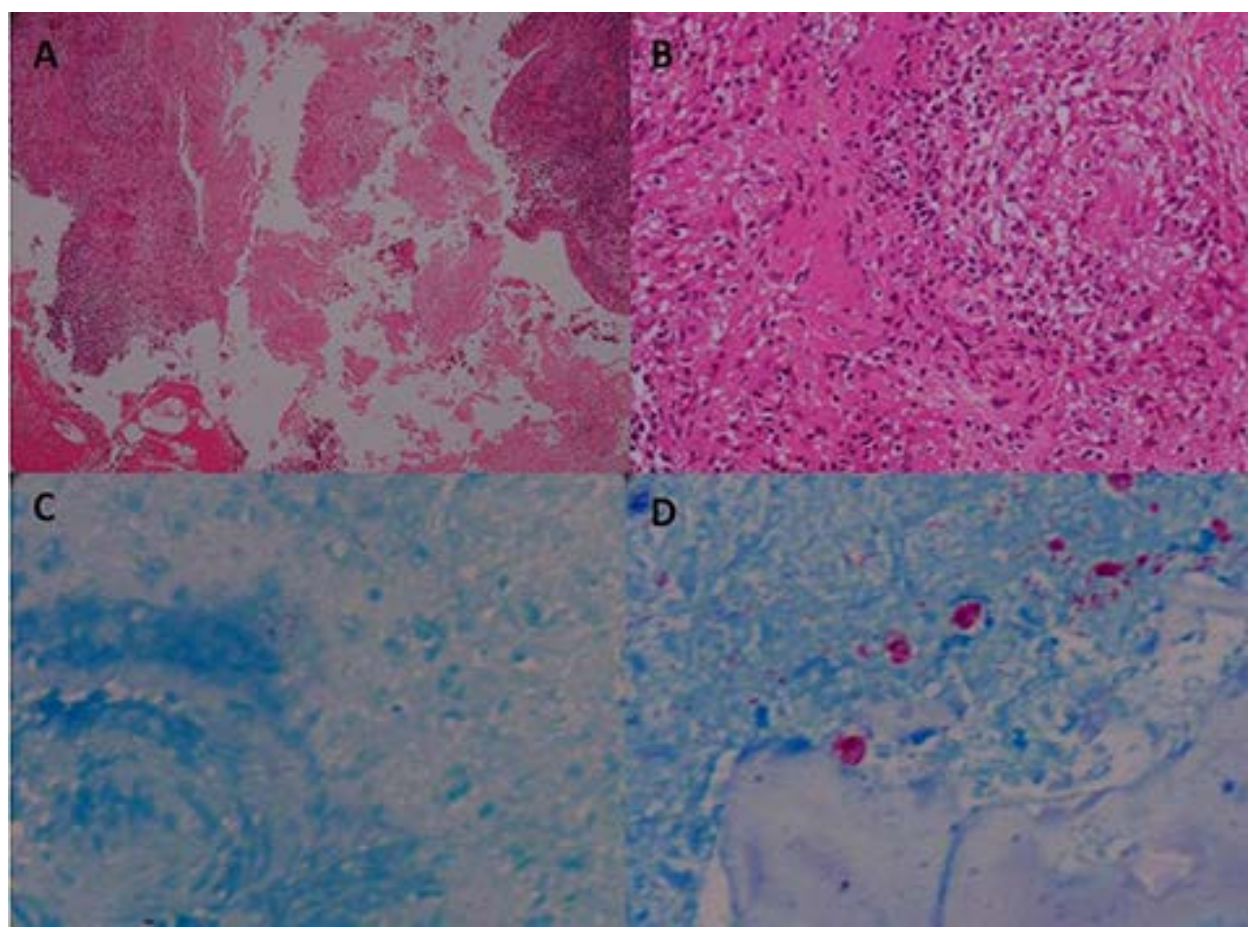

Figure 4. Endobronchial biopsy showing (A) granulomas and caseous necrosis in case 1 ( $\mathrm{H} \& \mathrm{E}, 40 \times$ ), (B) caseating epithelioid granuloma in case $2(\mathrm{H \& E}, 400 \times$ ), (C, D) Ziehl-Neelsen stain demonstrates acid fast bacilli in both patients (Z\&N, $1000 \times$ ) 
Table 1. Clinical characteristics of patients with endobronchial tuberculosis

\begin{tabular}{|c|c|c|c|c|c|c|c|c|c|c|}
\hline $\begin{array}{l}\text { Patient } \\
\text { number }\end{array}$ & $\begin{array}{c}\text { Age } \\
\text { (years) }\end{array}$ & Sex & Symptoms & $\begin{array}{c}\text { Sputum for } \\
\text { AFB }\end{array}$ & $\begin{array}{c}\text { CXR } \\
\text { findings }\end{array}$ & $\begin{array}{l}\text { CT scan } \\
\text { findings }\end{array}$ & $\begin{array}{l}\text { EBTB } \\
\text { type }\end{array}$ & $\begin{array}{l}\text { Site of } \\
\text { EBTB }\end{array}$ & Treatment & Outcome \\
\hline Case 1 & 24 & Male & Cough & Positive & $\begin{array}{l}\text { Right pa- } \\
\text { racardiac } \\
\text { haziness }\end{array}$ & $\begin{array}{l}\text { Nodular infil- } \\
\text { trates in RML } \\
\text { and RLL }\end{array}$ & Caseating & $\begin{array}{l}\text { Right } \\
\text { bronchial } \\
\text { tree }\end{array}$ & $\begin{array}{c}\text { Six months } \\
\text { intermittent } \\
\text { ATT }\end{array}$ & $\begin{array}{c}\text { Bronchoste- } \\
\text { nosis RML } \\
\text { bronchus }\end{array}$ \\
\hline Case 2 & 57 & Male & Cough & Negative & $\begin{array}{l}\text { Infiltartes } \\
\text { in LUL }\end{array}$ & $\begin{array}{c}\text { b/l infiltartes, } \\
\text { tree-in-bud } \\
\text { pattern, } \\
\text { lingular } \\
\text { consolidation }\end{array}$ & $\begin{array}{l}\text { Case- } \\
\text { ating }\end{array}$ & $\begin{array}{l}\text { Left up- } \\
\text { per lobe }\end{array}$ & $\begin{array}{c}\text { Six months } \\
\text { intermittent } \\
\text { ATT }\end{array}$ & $\begin{array}{c}\text { Complete } \\
\text { healing No } \\
\text { bronchoste- } \\
\text { nosis }\end{array}$ \\
\hline
\end{tabular}

AFB — acid fast bacilli; CXR — Chest X-ray; CT — computed tomography; EBTB — endobronchial tuberculosis; RML — right middle lobe; RLL — right lower lobe; ATT — antitubercular therapy; LUL — left upper lobe

also demonstrated acid fast bacilli. Echocardiography revealed a hypoplastic main pulmonary artery, invisible right pulmonary artery, mild pulmonary artery hypertension and normal left ventricular systolic function. Right pulmonary artery agenesis with actively caseating endobronchial tuberculosis was diagnosed and treated with thrice weekly regimen consisting of isoniazid $600 \mathrm{mg}$, Rifampicin $450 \mathrm{mg}$, Pyrazinamide $1,500 \mathrm{mg}$ and Ethambutol 1,200 mg for initial 2 months followed by Isoniazid and Rifampicin in the next 4 months. The patient improved symptomatically and a repeated bronchoscopy after treatment completion showed resolution of the endobronchial lesion with significant narrowing of the lower lobe bronchus and stenosis of the middle lobe bronchus (Fig. 3B). The patient was doing well at last contact six months after completion of treatment.

\section{Case 2}

A 57-year-old male presented in November 2015 with cough and decreased appetite for 2 months. Cough was persistent despite taking several courses of antibiotics and cough suppressants. He had no other pulmonary or extrapulmonary symptoms. He worked in an office, was a never smoker and had no comorbid illness. Physical examination was unremarkable. Chest auscultation revealed bilateral normal breath sound with scant crackles on the left mammary area. Hemogram, liver and kidney functions were within normal limits. Human immunodeficiency virus serology was negative. Two consecutive sputum smears for acid fast bacilli were negative. Chest radiograph showed alveolar infiltrates in the left upper lobe suggesting tuberculosis. High resolution CT scan demonstrated patchy bilateral infiltrates in the lungs with tree-in-bud pattern and lingular consolidation (Fig. 2C, 2D). Flexible bronchoscopy showed mild narrowing of the left main and upper lobe bronchi with cheesy-white material covering the left upper lobe bronchial divisions (Fig. 3C). Bronchial washing smear was positive for acid fast bacilli and endobronchial biopsy demonstrated caseating epithelioid granuloma and clumps of acid fast bacilli confirming caseous endobronchial tuberculosis [Fig. 4B 4D). The patient received intermittent antitubercular therapy for 6 months similarly to case 1 (Table 1). He improved clinically and repeated bronchoscopy at the end of therapy showed complete resolution of the lesion without any significant bronchial stenosis (Fig. 3D).

\section{Discussion}

EBTB is a special form of tuberculosis mostly affecting people in their second or third decade with an incidence 3-5 times more common in females than males. The right bronchial tree is most commonly involved. Unrelenting cough with or without fever is the predominant symptom [1-4]. Sometimes patients may present with wheeze due to endobronchial obstruction or bronchostenosis mimicking asthma [5], foreign body aspiration [6], and malignancy [7]. Thus, a clinical diagnosis is very difficult, and bronchoscopy is crucial in early diagnosis of EBTB.

Bronchoscopically, EBTB is classified into seven types, namely actively caseating, edematous-hyperemic, fibrostenotic, tumorous, granular, ulcerative, and nonspecific bronchitic [10]. Actively caseating lesions are those where the bronchial mucosa is swollen, hyperemic, and diffusely covered with whitish cheese-like material. This form is usually associated with luminal narrowing at diagnosis irrespective of 
the presence or absence of granulation tissue. In the edematous-hyperemic type, the bronchial lumen is almost always narrowed due to severe mucosal swelling with surrounding hyperemia. The tumorous type presents as endobronchial mass mimicking lung cancer. Granular variety appears like scattered grains of boiled rice on bronchial surface, whereas mucosal ulcerations may be seen in the ulcerative type. Nonspecific bronchitic form is characterized by mild mucosal swelling and/or hyperemia. Different forms of EBTB may be present concomitantly in a single patient and one form may transform to another during the course of treatment before final healing or progression to bronchostenosis. Edematous hyperemic and active caseating types have the highest propensity for progression to fibrostenotic variety, whereas ulcerative and nonspecific bronchitic types are the milder forms with excellent prognosis where complete healing usually occurs in 2-3 months of treatment. Tumorous EBTB has a highly unpredictable course with worst possible prognosis where new tumorous lesions may appear even after adequate duration or completion of treatment, and often leads to complete luminal obstruction [10]. Female sex, duration of symptoms longer than four weeks and no past history of tuberculosis are reported as independent predictors of concomitant EBTB in patients with active pulmonary tuberculosis. About one-fifth of patients end up having significant bronchostenosis with luminal narrowing experienced by more than one-third. The initial length of airway involvement and low forced expiratory volume in one second are risk factors for persistent bronchostenosis [4].

The pathogenesis is yet to be understood completely. The proposed mechanisms of endobronchial involvement are direct extension from adjacent parenchymal focus, implantation of organisms from the infected sputum, hematogenous dissemination, lymph node erosion into the bronchus, and through lymphatic drainage from parenchyma to the peribronchial region [11]. Chest radiographs may be normal or show parenchymal infiltrates, atelectasis, and obstructive hyperinflation. CT scan is helpful in assessing the length of stenotic segment, peribronchial thickness, luminal patency and response to treatment [3].

Surprisingly, expectorated sputum smear positivity rate is low in EBTB [1-4]. Bronchoscopy is helpful in early diagnosis as well as in predicting the course of disease [1, 10]. Histopathology of endobronchial biopsy is essential for diagnosis as bronchial lavage microbiology may be negative. The diagnostic yield is higher with combination of different bronchoscopic samplings [1, 8].

The treatment is similar to pulmonary tuberculosis with standard antitubercular drugs. Most patients respond to this regimen with a residual sequel of airway stenosis in about one-fifth of them. Corticosteroids are often used with intent to prevent or reduce bronchostenosis. However, bronchostenosis seems to be inevitable despite treatment [1-4]. The role of corticosteroids in EBTB remains controversial. Two randomized trials in children conducted in the 1960s, when effective antitubercular drugs were not available, showed favorable response in the steroid groups $[12,13]$, whereas the only trial conducted in adult patients failed to demonstrate any benefits of steroids [14]. Another study found that age $>$ 45 years, fibrostenotic subtype and $>90$ days between onset of symptom to the initiation of antituberculosis chemotherapy were independent predictors of persistent airway stenosis, and oral corticosteroids did not reduce the frequency of airway stenosis [15]. In view of this conflicting evidence, we did not use steroids in our patients. Furthermore, our patients received thrice weekly regimen under the revised national tuberculosis control program in contrast to other studies where daily therapy was used. In a previous series, six months of daily antitubercular therapy without corticosteroid was shown to be effective in managing tumorous EBTB in four patients [16]. The successful use of intermittent chemotherapy along with steroids has been reported in four patients with EBTB [8, 9]. We found remarkable improvement in both patients after 6 months of antitubercular therapy without steroids; however, significant residual bronchial narrowing was noted in the first case. Because this patient also had right pulmonary artery agenesis with hypoplastic right lung, it is difficult to ascertain whether bronchial narrowing is purely a consequence of disease or partly developmental due to lung hypoplasia. The long duration of symptoms in this patient prior to treatment might have aggravated the airway narrowing as well.

In conclusion, a high index of suspicion is required for early detection of EBTB. Bronchoscopy is essential for the diagnosis and assessment of treatment response. Short course intermittent chemotherapy of 6 months without steroids may be adequate for successful management of caseating endobronchial tuberculosis. 


\section{Conflict of interest}

\section{The authors declare no conflict of interest.}

\section{References:}

1. 1. Sahin F, Yıldız P. Characteristics of endobronchial tuberculosis patients with negative sputum acid-fast bacillus. J Thorac Dis. 2013; 5(6): 764-770, doi: 10.3978/j.issn.20721439.2013.12.15, indexed in Pubmed: 24409353.

2. Hoheisel G, Chan BK, Chan $\mathrm{CH}$, et al. Endobronchial tuberculosis: diagnostic features and therapeutic outcome. Respir Med. 1994; 88(8): 593-597, indexed in Pubmed: 7991884.

3. Lee JH, Park SS, Lee DH, et al. Endobronchial tuberculosis. Clinical and bronchoscopic features in 121 cases. Chest. 1992; 102(4): 990-994, indexed in Pubmed: 1395814.

4. Jung SS, Park HS, Kim JO, et al. Incidence and clinical predictors of endobronchial tuberculosis in patients with pulmonary tuberculosis. Respirology. 2015; 20(3): 488-495, doi: 10.1111/ resp.12474, indexed in Pubmed: 25620110.

5. Williams DJ, York EL, Nobert EJ, et al. Endobronchial tuberculosis presenting as asthma. Chest. 1988; 93(4): 836-838, indexed in Pubmed: 3349843.

6. Park MJ, Woo IS, Son JW, et al. Endobronchial tuberculosis with expectoration of tracheal cartilages. Eur Respir J. 2000; 15(4): 800-802, indexed in Pubmed: 10780776.

7. Singla R, Kumar A, Chauhan D, et al. Endobronchial tuberculosis presenting as tumorous mass. Indian J Chest Dis Allied Sci. 2007; 49(1): 45-47, indexed in Pubmed: 17256567.

8. Roy PP, Dey SK, Sarkar A, et al. Diagnosis of three cases of endobronchial tuberculosis presenting as unresolved pneumonia, following fiberoptic bronchoscopic biopsy. Lung India.
2010; 27(3): 185-188, doi: 10.4103/0970-2113.68316, indexed in Pubmed: 20931046.

9. Patel SM, Iyer A, Jayalakshmi TK, et al. Endobronchial tuberculosis mimicking malignancy. Lung India. 2015; 32(5): 508-510, doi: 10.4103/0970-2113.164169, indexed in Pubmed: 26628772.

10. Chung HS, Lee JH. Bronchoscopic assessment of the evolution of endobronchial tuberculosis. Chest. 2000; 117(2): 385-392, indexed in Pubmed: 10669679.

11. Smart J. Endo-bronchial tuberculosis. British Journal of Tuberculosis and Diseases of the Chest. 1951; 45(2): 61-68, doi: 10.1016/s0366-0869(51)80003-0.

12. Nemir RL, Cardona J, Vaziri F, et al. Prednisone therapy as an adjunct in the treatment of lymph node-bronchial tuberculosis in childhood. A double-blind study. Am Rev Respir Dis. 1963; 88(3): 189-198, doi: 10.1164/arrd.1963.88.2.189, indexed in Pubmed: 14045223.

13. Nemir RL, Cardona J, Vaziri F, et al. Prednisone as an adjunct in the chemotherapy of lymph node-bronchial tuberculosis in childhood: a double-blind study. II. Further term observation. Am Rev Respir Dis. 1967; 95(3): 402-410, doi: 10.1164/ arrd.1967.95.3.402, indexed in Pubmed: 5335164.

14. Park IW, Choi BW, Hue SH. Prospective study of corticosteroid as an adjunct in the treatment of endobronchial tuberculosis in adults. Respirology. 1997; 2(4): 275-281, indexed in Pubmed: 9525297.

15. Um SW, Yoon YS, Lee SM, et al. Predictors of persistent airway stenosis in patients with endobronchial tuberculosis. Int J Tuberc Lung Dis. 2008; 12(1): 57-62, indexed in Pubmed: 18173878.

16. De S. Effect of antitubercular treatment on tumorous endobronchial tuberculosis. J Bronchology Interv Pulmonol. 2011; 18(2): 171-175, doi: 10.1097/LBR.0b013e318217ccea, indexed in Pubmed: 23169090. 